\title{
The Role of Public Health Nurses in Japanese Long-term Care Prevention Projects in the Community
}

Mai Kabayama*, Kei Kamide, Kazue Sakakibara and Kazuo Hayakawa

Division of Health Sciences, Osaka University Graduate School of Medicine, Japan

*Corresponding author: Mai Kabayama RN, PHN, MS, 1-7, Yamadaoka, Suita, Osaka 565-0871, Japan, Tel: 6-6879-2554; E-mail: kabayama@sahs.med.osakau.ac.jp

Received date: March 20, 2014, Accepted date: May 09, 2014, Published date: May 12, 2014

Copyright: (c) 2014 Kabayama M, et al. This is an open-access article distributed under the terms of the Creative Commons Attribution License, which permits unrestricted use, distribution, and reproduction in any medium, provided the original author and source are credited.

\begin{abstract}
As the frontrunner of ageing countries, we would like to introduce the role of public health nurses in Japanese long-term care prevention projects in the community and our research on healthy longevity in this review article. Previous studies in Japan reported that lack of participation in social activities was significantly related to an increased risk to suffer from disability and subsequently requiring the application of Japanese long-term care insurance. As for primary/secondary prevention for old populations, public health nurses are expected to develop and utilize the social capital in health promotion interventions at individual and community levels in Japan. Since 2006, long-term care insurance was revised focusing on preventive care by detecting people aged 65 years and older who are at high risk of needing future care or support. There will be increasing demand for health care professionals to promote a community's overall health status in cost-effective ways, and public health nurses should play an important role to make it.
\end{abstract}

Keywords: Aged society; Community; Long-term care prevention; Public health nurse; Old-old; Young-old

\section{Introduction}

According to the Japanese national census, over the past 50 years the percentage of the older population has increased fourfold from $5.7 \%$ in 1960 to $23.1 \%$ in 2010 [1]. This increasing rate is the fastest in the world. As the frontrunner of ageing countries, we would like to introduce the role of public health nurses in Japanese long-term care prevention projects in the community in this article. In this article, the following definition applies to public health nursing according to American Public Health Association: "Public health nursing is the practice of promoting and protecting the health of populations using knowledge from nursing, social, and public health sciences" [2].

\section{Primary prevention for long-term care}

The percentage of the older population is estimated to continue increasing rapidly and reach up to $26.8 \%$ in 2015 as reported by the National Institute of Population and Social Security Research [3]. Japan will face a super-aged society in the near future, in which $40 \%$ of the population will be over 65years-of-age [3]. However, prolongation of life expectancy is inevitably associated with greater numbers of frail old people who need help in daily activities. The percentage of the oldold population (aged 75 years and over) in 2012, comprising more frail people compared to the young-old population, exceeded $11.9 \%$ of the nation's population in Japan [3].

In such a situation, many older Japanese wish to be healthy for their entire life and continue to live in their hometown with a sense of security until the end of their life. Under such circumstances, we should establish a society in which old people can enjoy a healthy, satisfying life through social participation and contribution. For an active ageing society, the World Organization (WHO) policy framework requires action on the following three basic pillars: Health, Participation and Security. As for the policy framework, enhanced participation in social activities is required to attain the goal of active aging [4]. Also in Japan, the government started the Health Japan Project (the 2nd term) in April 2013, which is a 2nd version of a 10year national campaign intended to prolong length of healthy life and to improve quality of life. As many older retired peoples are expected to have more time to participate in various activities in the community, participation in social activities would increasingly play a key role in contributing to the health of older adults in today's aging society in Japan [5].

Previous studies have investigated the association between participation in social activities and various health outcomes [6]. In a study in Sweden, it was found that social participation was the strongest predictor of low physical activity [7]. Also in a study conducted in Japan reported that lack of participation in social activities was significantly related to an increased risk to suffer from disability and subsequently requiring the application of Japanese longterm care insurance (LTCI) [8]. In addition, participation in social activities is supposed to be very important in the community, since it may develop social capital. Social capital refers to the quantity and quality of social relationships such as formal and informal social connections as well as norms of reciprocity and trust that exist in community [9]. Many recent studies have found that high levels of social capital are associated with better health $[10,11]$.

Since public health nurses are the main community health practitioner who had been promoted and protected the health of populations, as for primary/secondary prevention (Figure 1) for old populations, public health nurses are now expected to develop and utilize the social capital in health promotion interventions at individual and community levels in Japan [12]. 


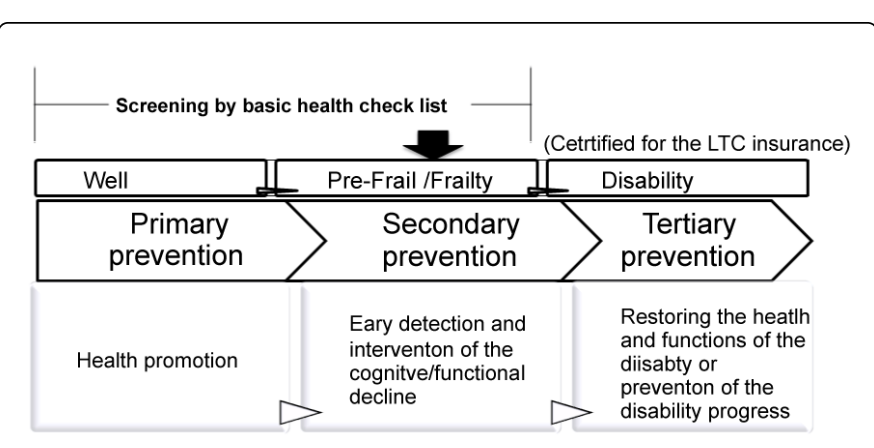

Figure 1: Prevention steps for long-term care

LTC; long term care

\section{Secondary prevention for long-term care}

An increase in long-term care expenses due to the increase of an aging population can affect the insurance premiums of both the old and the actively working generation [13]. With the comprehensive reform of social security and the tax system, establishing an integrated community care system and ensuring the sustainability of the Japanese long-term care insurance (LTCI) system is an essential topic [13]. LTCI in Japan was introduced in 2000 to cover social care for 2 million people aged 65 years and older, and the number of insured people under LTCI doubled by 2006 [14]. Since 2006, LTCI was revised focusing on preventive care by detecting people aged 65 years and older who are at high risk of needing future care or support [15]. The preventive care project provides community-based exercise programs and programs to improve cognitive function and malnutrition status. Many local governments are trying to detect community dwelling older people who are at high risk, using the basic health check list called "Kihon Checklist" (Table 1) [14]. The basic health check list consists of 25 items and seven categories (daily life, physical ability, nutrition, oral condition, seclusion, forgetfulness, and mind) for the screening of older people who have functionally or cognitively declined [16,17]. A subject is identified as showing "low physical strength" if they score three or more negative responses in questions 6-10. "Low nutritional status" is assessed by answers to both questions 11 and 12 , with negative answer indicating lower status, and "low oral function" was defined as two or more negative responses in questions 13-15. A subject is identified as showing frailty if they answered at least 10 or more negative responses in questions 1-20 (interpreted "Overall low score on questions 1-20" in Table 1) [17]. The target people for the secondary preventive care project, who are at high risk of needing future care or support, are defined by the criteria of the Japan Ministry of Health, Labor and Welfare as those who show lower function in at least physical strength, nutritional status, oral function and overall low score on questions 1-20. When we approach them, we also should refer the categories of "houseboundness", "low cognitive function" and "depression risk" to make preventive interventions more effective. "Houseboundness" referred people who answered "no" to question 16. "Low cognitive function" referred to people who had at least one or more negative conditions in questions 18-20, and "depression risk" referred to people who had two or more negative responses (questions 21-25) [16,17].

Various preventive intervention programs were provided in the community by the local government and have been proved to be effective for preventing functional or cognitive decline of older people. Public health nurses are playing an important role to perform these preventive intervention programs as the practitioner in the community. However, it is pointed out that there is a large gap between the number of people participating in preventive intervention programs and the people who are screened out as having any health problems to prevent further decline [14]. Though the preventive programs are effective for those who had participated in, it is not efficient considering the number of older people dwelling in the community. Therefore, many local governments are now trying to shift these preventive intervention programs by not only focusing on the people who are screened out as being functionally or cognitively declined (at the second prevention stage), but also on healthy older population (at the primary prevention stage) together, so as to promote the health status of the whole community. Designing longterm care prevention interventions to promote a community's overall health status in cost-effective ways is the key to establish a society where older people can live with a sense of security in their community. To realize it, a macroscopic integration and cooperation among industries, education institutions, administration and community through an interdisciplinary approach including medical science, nursing science, nursing care, study of gerontology, social welfare, social science, engineering, psychology, economics, religion and ethics should be made [5]. As the community health practitioner, public health nurses are expected to make the best use of their practice characteristics, "focusing on the health needs of an entire population", "conducting assessment of population health using a comprehensive, systematic approach", "developing and implementing communitywide health promotion programs", and "working in community partnerships and interdisciplinary teams" [18]. Although public health nurses have the advanced skills in population/community health management, their role has been underutilized and not well understood $[19,20]$. Public health nurses should now play their emerging role to develop those primary and secondary prevention projects utilizing their skills and resources, especially in this world's most aged society Japan. 
Citation: Kabayama M, Kamide K, Sakakibara K, Hayakawa K (2014) The Role of Public Health Nurses in Japanese Long-term Care Prevention Projects in the Community. J Nurs Care 3: 166. doi:10.4172/2167-1168.1000166

Basic health check list for those over 65years old

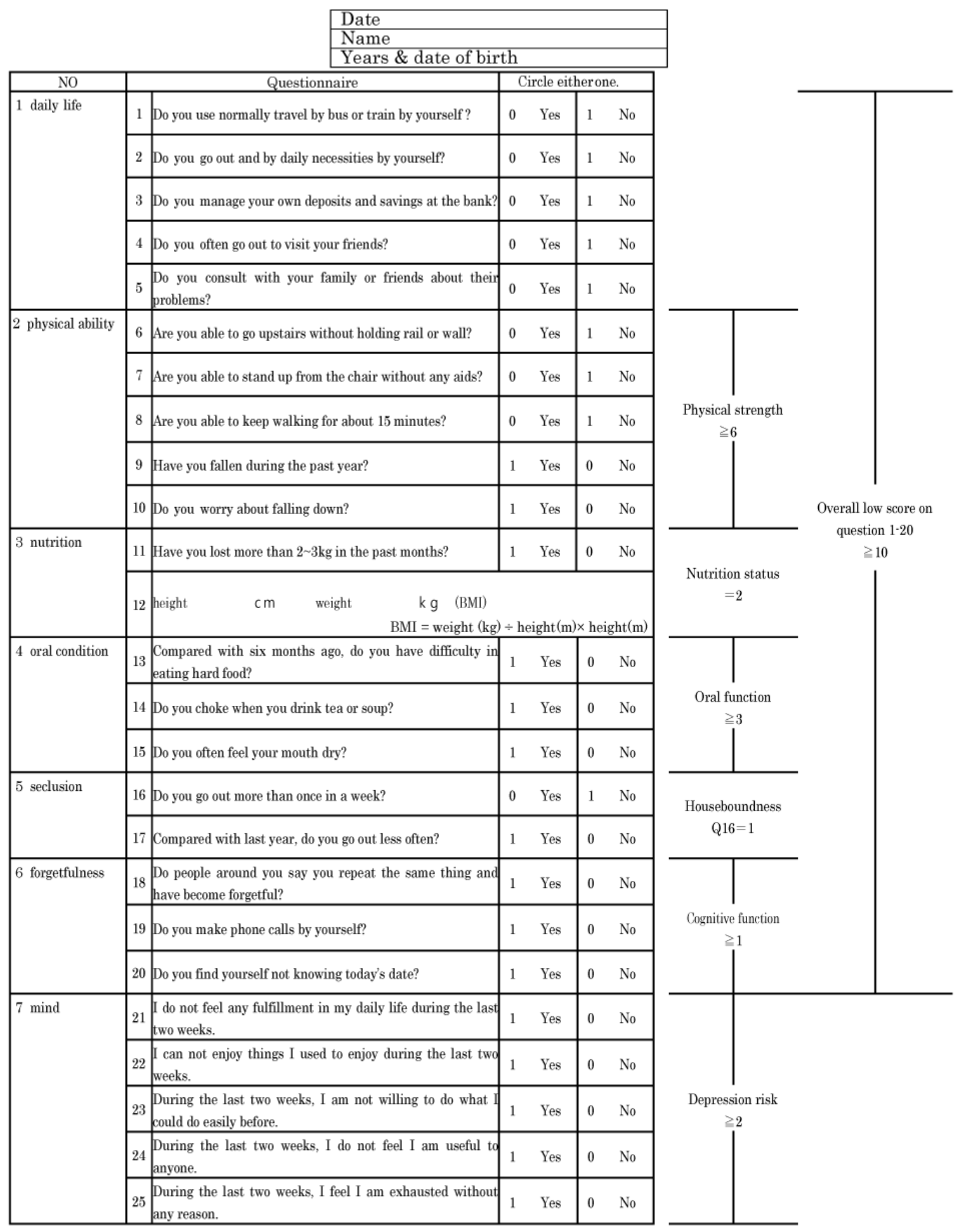

http://eng.amda-imic.com/oldpage/amdact/PDF/eng/over65check·e.pdfOAMDAInternational Medical Information Center 2008

Table 1: Basic health check list (Kihon Checklist) for older people (aged 65 or more) in Japan 
The basic health check list is a 25 -item self-rated questionnaire consists of seven categories. Older persons (aged 65 years or more) who need some intervention are screened out by the criteria defined by the Ministry of Health, Labour and Welfare in Japan [16].

This Table is adopted from the web page of the Association of Medical Doctors in Asia [25].

\section{Our research on healthy longevity}

"Which factors influences the healthy longevity?" is the key for the practice of LTC prevention project. There has been considerable research on the influence of these factors on morality from birth to older age but remarkably little research on how these factors affect the likelihood that a person will survive and remain healthy to an oldest old age [21]. Starting with the research premise of healthy longevity in Japan, we started a longitudinal cohort study for the aged population to clarify factors contributing to healthy longevity. It is the study about Septuagenarians, Octogenarians, Nonagenarians Investigation with Centenarians (SONIC study). Aims of the SONIC study are to investigate age differences and similarities in factors influencing healthy aging and psychological well-being including psychological (cognition, change in emotion and compensation; personality, psychological development), social (socio-economic status, social relationship), medical, dental and nutritional aspects [22]. Study participants include more than three thousand, septuagenarians aged 69-71 years, octogenarians aged 79-81 years, nonagenarians aged 89-91 years, and centenarians aged 100 and over collected from four urban and rural towns in Japan. Most studies focusing on centenarians are aiming to investigate factors contributing to healthy longevity [23]. However, SONIC is supposed to be unique and more practicable than centenarian studies because of including 70, 80, 90, 100 years and more. Centenarians are not always good models of healthy longevity. Most of the centenarians are lying on bed especially in Japan [24]. We are looking for targets to realize the prevention of LTC from the public health nurse's standpoint.

\section{Conclusion}

In order to realize a better aged society in which all people can have healthy, satisfying lives while supporting each other, there will be increasing demand for health care professionals who have the skills to manage the health of the population and communities. These health care professionals such as public health nurses are especially essential in a super-aged country, Japan, as mentioned above. Since public health nurses have the knowledge and skills to "work in community partnerships and with interdisciplinary teams" and "develop health promotion and disease prevention programs that are culturally appropriate and cost-effective" [20], they should play an important role for Japanese long-term care prevention projects in the community.

\section{Acknowledgements}

We greatly appreciate for all members of the SONIC study, especially, Dr. Yasuyuki Gondo, Dr. Takeshi Nakagawa (Dept. of Human Science, Osaka Univ.), Dr. Kazunori Ikebe (Dept. of Dentistry, Osaka Univ.), Dr. Hiromi Rakugi, Dr. Ryosuke Oguro, Dr. Chikako Nakama (Dept. of Geriatric Medicine, Osaka Univ.), Dr. Yasumichi Arai (Dept. of Geriatric Medicine, Keio Univ.), Dr. Yukie Masui, Dr. Tatsuro Ishizaki, Dr. Ryutaro Takahashi (Research Ins. Tokyo Metropolitan Ins. of Gerontology). We would also like to express our gratitude to the suggestive comments from Dr. Peter Martin (Iowa State University).

\section{References}

1. Cabinet Office, Government of Japan (2014) Annual Report on the Aging Society.

2. American Public Health Association, Public Health Nursing Section (2013) The definition and practice of public health nursing: A statement of the public health nursing section. Washington, DC: American Public Health Association.

3. Japanese National Institute of Population and Social Security Research (2012). Estimated population.

4. World Health Organization (2002) Active Ageing: a Policy Framework. Geneva, Switzerland: WHO.

5. Arai H, Ouchi Y, Yokode M, Ito H, Uematsu H, et al. (2012) Toward the realization of a better aged society: Messages from gerontology and geriatrics. Geriatr Gerontol Int 12:16-22.

6. Abbott S (2010) Social capital and health: The role of participation. Social Theory \& Health 8: 51-65.

7. Lindström M, Hanson BS, Östergren PO (2001) Socioeconomic differences in leisure-time physical activity: the role of social participation and social capital in shaping health related behaviour. Social Science \& Medicine 52: 441-451

8. Hirai H, Kondo K, Ojima T, Murata C (2009) Examination of risk factors for onset of certification of long-term care insurance in communitydwelling older people: AGES project 3-year follow-up study [in Japanese]. Nihon Koshu Eisei Zasshi 56: 501-512.

9. Berkman L, Kawachi I (2000) Social Epidemiology. New York: Oxford University Press.

10. Hyppa MT, Maki J (2003) Social participation and health in a community rich in stock of social capital. Health Education Research Theory and Practice 18: 770-779.

11. Kawachi I, Kennedy BP (1999) Income inequality and health: Pathways and mechanisms. Health Services Research 34: 215-227.

12. Eriksson M (2011) Social capital and health - implications for health promotion. Global Health Action 4: 5611.

13. Ministry of Health, Labour and Welfare (2013) Health and Welfare Bureau for the Elderly.

14. Fukutomi E, Kimura Y, Wada T, Okumiya K, Matsubayashi K (2013) Long-term care prevention project in japan. Lancet 381: 116.

15. Ministry of Health, Labour and Welfare(2006) Reforms Concerning the System of Long-term Care Insurance.

16. Ministry of Health, Labour and Welfare(2012). Manual for the long-term care prevention.

17. Fukutomi E, Okumiya K, Wada T, Sakamoto R, Ishimoto Y et al. (2013) Importance of cognitive assessment as part of the "Kihon Checklist" developed by the Japanese Ministry of Health, Labour and Welfare for prediction of frailty at a 2-year follow up. Geriatr Gerontol Int 13: 654-662.

18. Robertson JF, Baldwin KB (2007) Advanced Practice Role Characteristics of the Community/Public Health Nurse Specialist. Clinical Nurse Specialist 21: 250-254.

19. Hemstrom M, Ambrose M, Donahue G, Glick L, Lai HL et al. (2000) The Clinical Specialist in Community Health Nursing: A Solution for the 21st Century. Public Health Nursing 17: 386-391.

20. Robertson JF (2004) Does Advanced Community / Public Health Nursing Practice Have a Future? Public Health Nursing 21: 495-500.

21. Yi Z, Vaupel JW, Zhenyu X, Chunyuan Z, Yuzhi L (2001) The Healthy Longevity Survey and the Active Life Expectancy of the Oldest Old in China. Population: An English Selection 13: 95-116.

22. Inomata C, Ikebe K, Kagawa R, Okubo H, Sasaki S, et al. (2014) Significance of occlusal force for dietary fibre and vitamin intakes in independently living 70-year-old Japanese: from SONIC Study. Journal of Dentistry 42: 556-564. 
Citation: Kabayama M, Kamide K, Sakakibara K, Hayakawa K (2014) The Role of Public Health Nurses in Japanese Long-term Care Prevention Projects in the Community. J Nurs Care 3: 166. doi:10.4172/2167-1168.1000166

Page 5 of 5

23. Rosa G, Martin P, Gondo Y, Hirose N, Ishioka Y, et al. (2014) Examination of Important Life Experiences of the Oldest-Old: CrossCultural Comparisons of U.S. and Japanese Centenarians. J Cross Cult Gerontol 29: 109-130

24. Arai Y, Hirose N (2013) Functional status, morbidity, and mortality of centenarians [in Japanese]. Clinical Calcium 23: 45-50.
25. The Association of Medical Doctors of Asia (AMDA) International Medical Information Center (2008) Basic health check list for those over 65 years old 